\title{
Power Quality Improvement by using Dynamic Voltage Restorer
}

Marrapu Manisha ${ }^{1}$, Pakalapati Sree Harshitha ${ }^{2}$, Samudrala Maneesh ${ }^{3}$, Sunkari Balaji ${ }^{4}$, P. Shyam Kiran ${ }^{5}$

${ }^{1}$ STUDENT, Department of EEE, Lendi Institute of engineering and technology, INDIA, manishamarrapu13587@gmail.com

${ }^{2}$ STUDENT, Department of EEE, Lendi Institute of engineering and technology, INDIA, harshithapakalapati2@gmail.com

${ }^{3}$ STUDENT, Department of EEE, Lendi Institute of engineering and technology, INDIA, maneeshsamudrala578@ gmail.com

${ }^{4}$ STUDENT, Department of EEE, Lendi Institute of engineering and technology, INDIA, sbalaji1460@gmail.com

${ }^{5}$ ASSOCIATE PROFESSOR, Department of EEE, Lendi Institute of engineering and technology, INDIA, shyamjan26@ gmail.com

Received Date : August 05, 2021 Accepted Date : August 25, 2021 Published Date : September 07, 2021

\begin{abstract}
The integration of renewable energy sources, smart grid systems and extensive usage of power electronic devices, micro-controlled based device, variable speed drives etc. causes a number of power quality issues including electrical harmonics, voltage sag, voltage swell and imbalance creates an impact on the efficiency of electrical equipment. the energy maintaining poor power quality will affect consumers and their utility equipment's. Power quality means quality of the normal voltage supplied to your facility. Voltage provided should be as close as possible to nominal voltage. The waveform must be pure sine wave free from any harmonics and other disturbances. The growing use of microprocessors and electronic equipment has made us to focus on power quality. Equipment and machinery can be damaged or even fail when subjected to power anomalies. Some of the power quality issues are voltage sag, swell, harmonics, flicker, interruption etc. Among these issues voltage sag is an important issue. This paper investigates about the causes of voltage sag, consequences and its mitigation. Many mitigation devices are available and the most economic effective solution is Dynamic Voltage Restorer (DVR). Simulation has been carried out to evaluate performance. A DVR is simulated in MATLAB/SIMULINK using synchronous reference frame theory.
\end{abstract}

Key words : Power Quality, Harmonics, Voltage Sag, Voltage Swell, DVR, MATLAB.

\section{INTRODUCTION}

Most of the loads used in domestic, commercial and industries are inductive (non-linear) in nature. Some of the examples of nonlinear loads are uncontrolled \& controlled rectifiers; variable speed drives both $\mathrm{AC}$ and DC, uninterrupted power supplies, arc furnaces, electronic ballast, programmable logic controllers etc. All these devices are economical, flexible and energy efficient, they may deteriorate power quality by injecting harmonic current into the power system and consuming excessive reactive power, as they are drawing nonsinusoidal current from utilities, this can cause many problems such as resonance, excessive neutral currents, low power factor etc. Harmonics produces harmonic current, poor power factor, unbalance, voltage sag \& swell, reactive power burden. A harmonic current passing through the supply impedances creates problem of voltage harmonics and voltage unbalance at the Point of common coupling (PCC). The extensive application of non-linear loads in domestic commercial industrial sector; causes power quality problems such as harmonic current, poor power factor, unbalance, voltage sag \&swell, reactive power burden etc.

Power quality problems in a distributed power system can be mitigated by using Active Power Filters (APFs) and Dynamic Voltage Restorer (DVR) can be used for compensation of reactive power andunbalanced loading in the distribution system. Removal of harmonicsin power system can be done in two ways:

(i) By providing a low impedance path to ground for harmonic signal, for this passive tuned filter can be used.

(ii)By injecting compensating signals which are in phase opposition with the harmonic signal present in the

system, this can be done by using active filters.

Series inductor allowing the reactive power control. Static DC bus capacitors and passive filters have been utilized to improve power quality (PQ) in a distribution system.

\section{SYSTEM TOPOLOGY}

Among the power quality problems (sags, swells, harmonics) voltage sags are the most severe disturbances. In order to overcome these issues the concept of custom power devices is introduced recently. One of those devices is the Dynamic Voltage Restorer (DVR), which is the most efficient and effective modern custom power device used in power distribution networks. DVR is a recently proposed series connected solid state device that injects voltage into the system in order to regulate the load side voltage. It is normally installed in a distribution system between the supply and the critical load feeder at the point of common coupling (PCC). Other than voltage sags and swells compensation, DVR can also gives other features like: line voltage harmonics compensation, reduction of transients in voltage and fault current limitations. the DVR consists of essentially a series connected injection transformer, a voltage source inverter (VSI), inverter output filter and an energy storage device connected to the dc-link. The power system upstream to DVR is represented by an equivalent voltage source and a source impedance. There are various circuit topologies and control schemes that can be used to implement a DVR.

In addition to voltage sags and swells compensation, DVR can also perform other tasks such as: line voltage harmonics compensation, reduction of transients in voltage and fault current limitations.

The general configuration of the DVR consists of an Injection/Booster transformer, a Harmonic filter, a Voltage Source Converter (VSC), DC charging circuit and a Control and Protection system.

The design of the DC bus capacitor depends on the energy storing capability needed during the transient condition. The required compensation is provided by the DVR. 


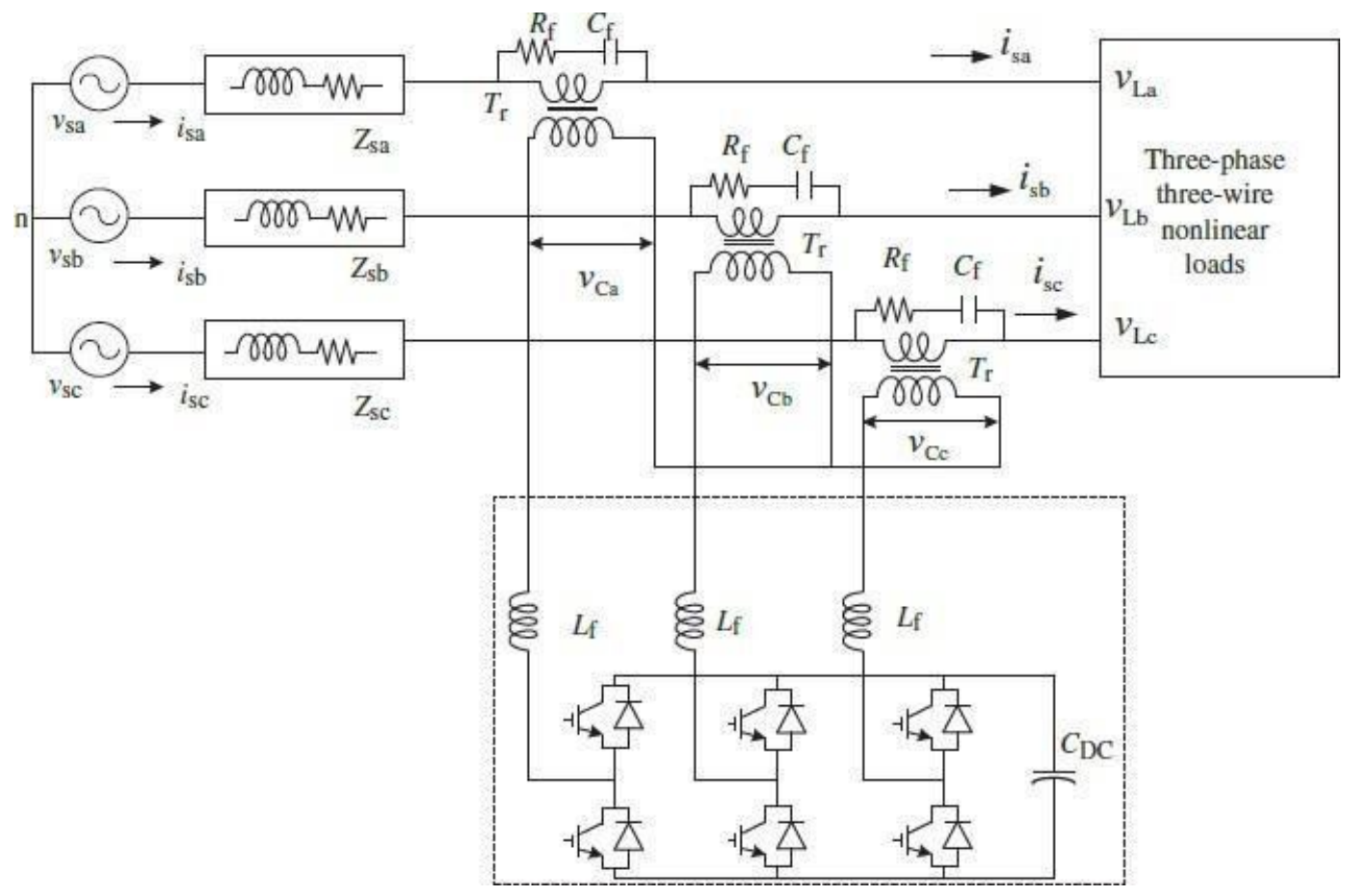

Fig.1 shows System configuration of three phase series Active Power Filters

\section{ACTIVE POWER FILTERS}

through three single-phase coupling transformers. A threephase VSC with a DC bus capacitor is used as a series active power filter. A small-rating $\mathrm{RC}$ filter is connected across secondary of each series transformer to eliminate high switching ripple content in the series active power filter injected voltage. The loads may include linear loads requiring elimination of voltage harmonics across them or voltage-fed nonlinear loads, such variable-frequency AC motor drives, as balanced harmonic-producing loads requiring elimination of supply current harmonics. It consists of a three-phase VSC connected in series with three-phase supply

A single series filter may be installed at the PCC for multiple diverse types of loads for the elimination of voltage harmonics across them. However, such a configuration is susceptible to danger under short-circuit condition in utility line and thus requires an adequate protection. The series APF is controlled to eliminate harmonics in the three-phase supply currents or distortion and unbalance in the PCC voltages by injecting suitable voltage in series with the supply.

For the voltage-fed nonlinear loads, which consist of a capacitive filter and an equivalent load at the DC link of a threephase diode rectifier, a series APF alone can effectively maintain sinusoidal supply currents. However, for the currentfed nonlinear loads, which consist of the series connection of a resistor and an inductor at the DC link of a three-phase diode rectifier or a three- phase thyristor bridge converter, a combined system of the shunt passive filters and a series active power filter needs to be employed to effectively maintain sinusoidal supply currents. The control algorithm of the series active filter to eliminate current harmonics is suitable for both the series active filter and hybrid configurations of a series active power filter with a shunt passive filter.

Moreover, for voltage-sensitive loads, to eliminate the voltage harmonics and unbalance and to maintain zero voltage regulation at $\mathrm{PCC}$, the series $\mathrm{APF}$ is directly controlled to inject sufficient voltage in series with the supply; that is, the sum of supply voltage and injected voltage becomes sinusoidal with desired amplitude across the loads.

\section{CONTROL ALGORITHM FOR ELIMINATION OF VOLTAGE HARMONICS (SRF THEORY):}

Many control schemes are reported for control ofDSTATCOM e.g Synchronous Reference Frame (SRF) theory, Instantaneous Symmetrical Component (ISCT) theory, Instantaneous Reactive Power (IRPT) theory, Icos $\Phi$ algorithm, Current Synchronous Detection (CDS) algorithm, power Balance theory (PBT), Adaline based algorithm etc. Generation of proper gating pulses for the IGBTs of VSC is very crucial for proper implementation of the load compensation. The advent of the low switching loss IGBTs has enabled the designers to shift from fundamental frequency switching to PWM (Pulse Width Modulation) based switching. Further, custom power being a relatively low power application, PWM methods offer a more flexible option than fundamental frequency switching methods favoured in FACTS applications. Though various topologies of VSC have been reported, single 3-phase VSC Bridge with six IGBT switches is widely reported for DVR. In this chapter performance of following algorithms used for reference current extraction and for generating PWM gating pulses for the inverter, have been studied. The control algorithm block diagram is shown in Fig 2. 


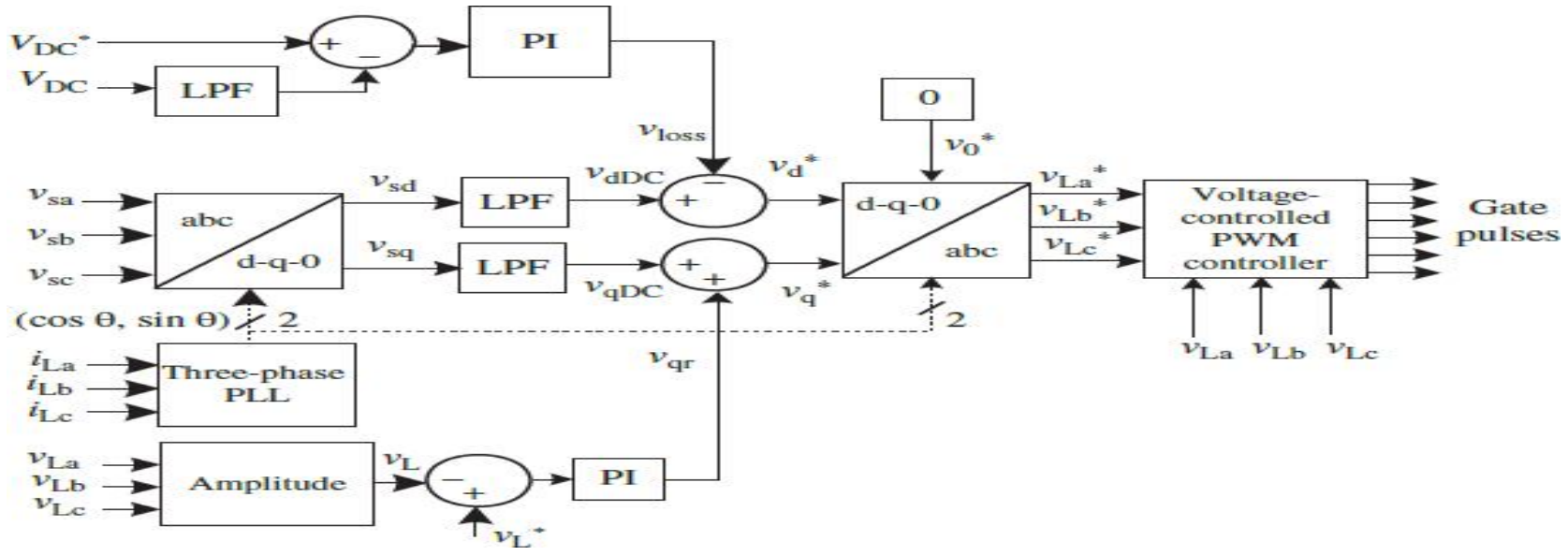

Fig 2. Shows Control scheme of a series APF for the elimination of voltage harmonics

The voltages at PCC (vs) are converted to the rotating reference frame using the Park's transformation. The harmonics and the oscillatory component of the voltages are eliminated using lowpass filters (LPFs). The components of voltages in the d-axis and q-axis are

$$
\mathrm{Vsd}=\mathrm{VdDc}+\mathrm{VdAc}, \mathrm{Vsq}=\mathrm{VqDc}+\mathrm{VqAc} .
$$

The compensation strategy for the compensation of voltage quality problems considers that the load terminal voltage should be of rated magnitude and undistorted in nature. In order to maintain the DC bus voltage of the self-supported capacitor of the VSC used as a series active filter, a PI (proportional-integral) controller is used at the DC bus voltage of the series AF and the output is considered as the voltage ( $\mathrm{V}_{\text {loss }}$ ) for meeting its losses. Therefore, the reference direct-axis load voltage is

$$
\mathrm{V}^{*} \mathrm{~d}=\mathrm{VdDC}-\text { Vloss. }
$$

The amplitude of load terminal voltage $\left(\mathrm{V}_{\mathrm{L}}\right)$ is controlled to its reference voltage $\mathrm{V}^{*}$ using another PI controller. The output of the PI controller is considered as the reactive component of voltage $\left(\mathrm{v}_{\mathrm{qr}}\right)$ for voltage control across the load terminal. The reference quadrature-axis load voltage is

$$
\mathrm{V} * \mathrm{q}=\mathrm{VqDC}+\mathrm{Vqr} \text {. }
$$

The reference load Voltages $\left(\mathrm{V}^{*} \mathrm{La}, \mathrm{V}^{*} \mathrm{Lb}, \mathrm{V}^{*} \mathrm{Lc}\right)$ in the abc frame are obtained from the reverse Park's transformation. The error between the sensed load Voltages (VLa, VLb, VLc) and the reference load voltages $\left(\mathrm{V}^{*} \mathrm{La}, \mathrm{V}^{*} \mathrm{Lb}, \mathrm{V}^{*} \mathrm{Lc}\right)$ is used over a PWM controller to generate gating pulses to the VSC of the series AF.

Three phase reference supply voltage (VLa*, VLb*, VLc*) are derived using sensed load voltages, terminal voltage (Vta, Vtb, $\mathrm{Vtc}$ ) and dc bus voltage (Vdc) of the DVR.SRF method is used to obtain the direct axis (Vd) and quadrature axis (Vq) components of load voltage. By Park's transformation three phase load voltage is converted to dqo frame. To synchronise these signals with the terminal voltage a three phase PLL is used.The dq components are passed through LPF to extract dc components of $\mathrm{Vd}^{*}$ and $\mathrm{Vq}^{*}$. To maintain dc bus voltage of self-supported capacitor, the error between sensed dc voltage and reference dc voltage $\left(\mathrm{Vdc}^{*}\right)$ are given to a PI controller and its output (Vcad) is considered.

To regulate the amplitude of the load voltage (VL) another PIcontroller is used. The amplitude VL at PCC is calculated as $\mathrm{VL}=(2 / 3(\mathrm{VLa} 2+\mathrm{VLb} 2+\mathrm{VLc} 2))$
The amplitude of load voltage and output of PI controller is considered as reactive component of voltage (Vqr) for voltage regulation of load terminal voltage added with dc component of $\mathrm{Vq}$ to generate $\mathrm{Vq}^{*}$. the reference q-axis load voltage is given as

$$
\mathrm{VLq} *=\mathrm{Vsq}(\mathrm{dc})+\mathrm{Vqr}
$$

The resultant voltages $\left(\mathrm{Vd}^{*}, \mathrm{Vq}^{*}, \mathrm{Vo}\right)$ are again converted into the reference supply voltages using reverse Park's transformation. Reference supply voltages (VLa*, VLb, VLc*) and the sensed load voltages (VLa, VLb, VLc) are used in PWM current controller to generate gating pulses for the switches.

\section{MATLAB/SIMULINK RESULTS OF DVR:}

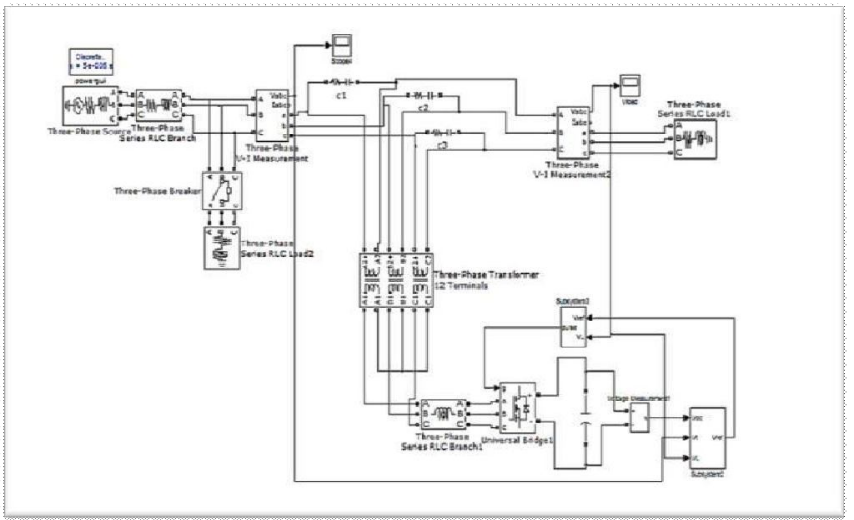

Fig 3 shows MATLB/Simulink model of DVR

In this system a DVR is introduced in the distribution system to compensate voltage sag. The DVR connected system consisting of three phase supply, three phase critical load, and the series injection transformer is modeled in MATLAB/ SIMULINK environment along with a sim power system toolbox and is shown

The simulation performance of the DVR is carried out using MATLAB/Simulink. The SRF control algorithm is considered to evaluate the effectiveness of both two topologies. these are as follows:

1. Power distribution system with DVR under balanced condition.

2.Power distribution system with DVR under unbalanced condition. 
Marrapu Manisha et al., International Journal of Emerging Trends in Engineering Research, 9(9), September 2021, 1282 - 1287

\section{FFT Analysis Under Balanced Condition}

Fundamental $(50 \mathrm{~Hz})=412.3$, THD $=0.96 \%$

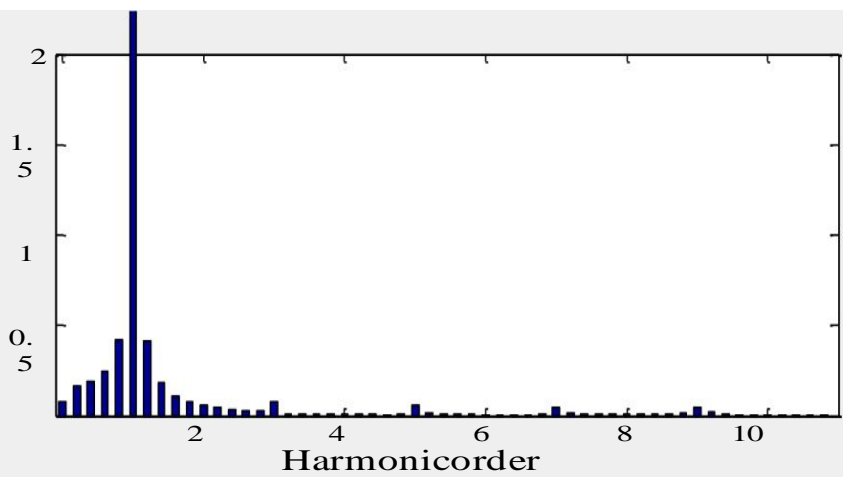

Fig.4: (i) showsTHD of source voltage

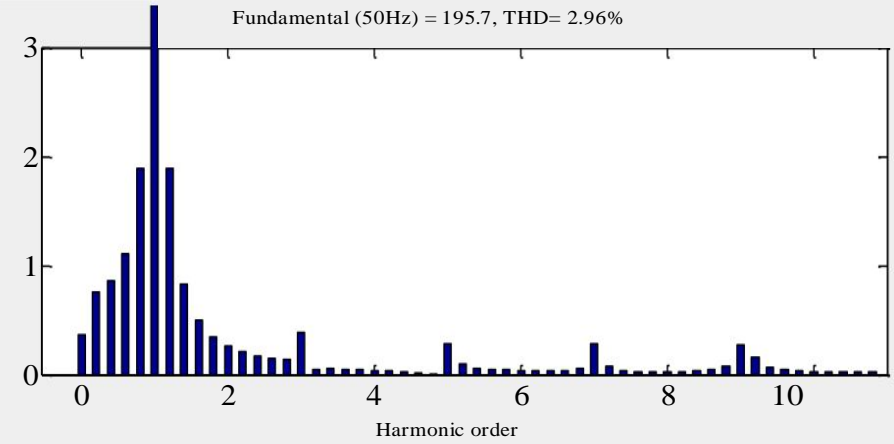

(ii) shows THD of load voltage

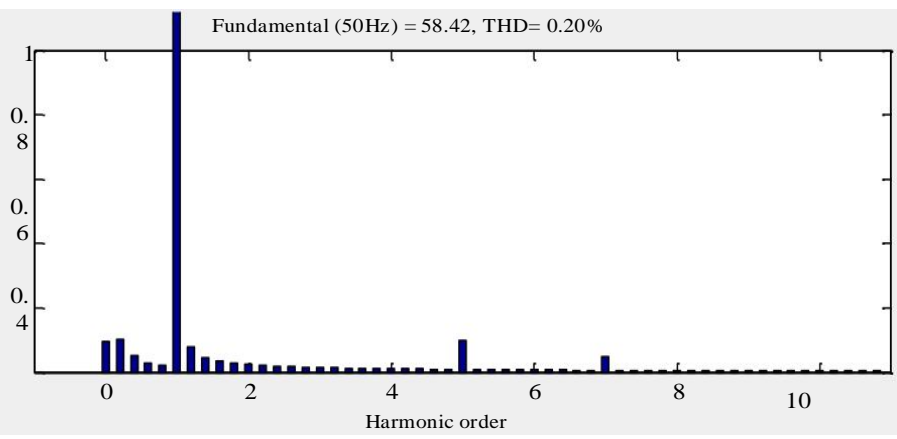

(iii) shows THD of source current

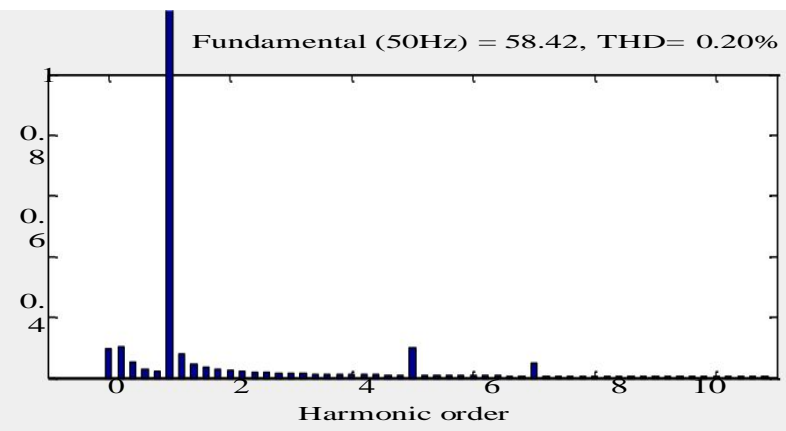

(iv) shows THD of load current

\section{FFT Analysis Under Unbalanced Condition}

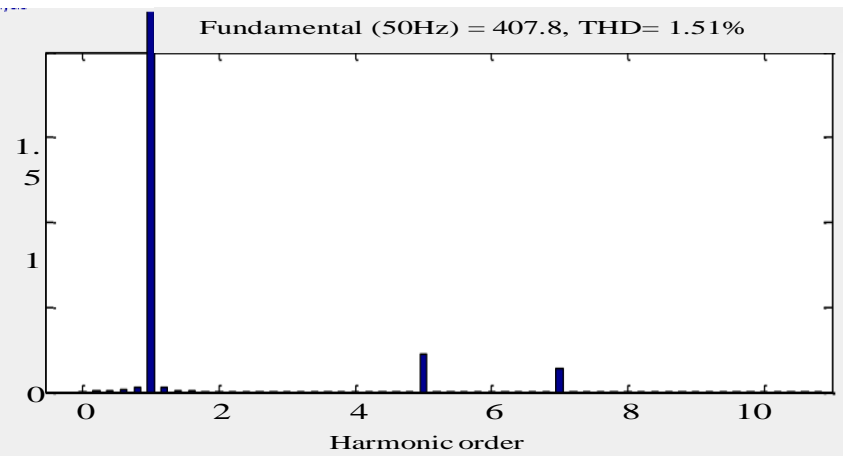

Fig.5: (i) shows THD of source voltage

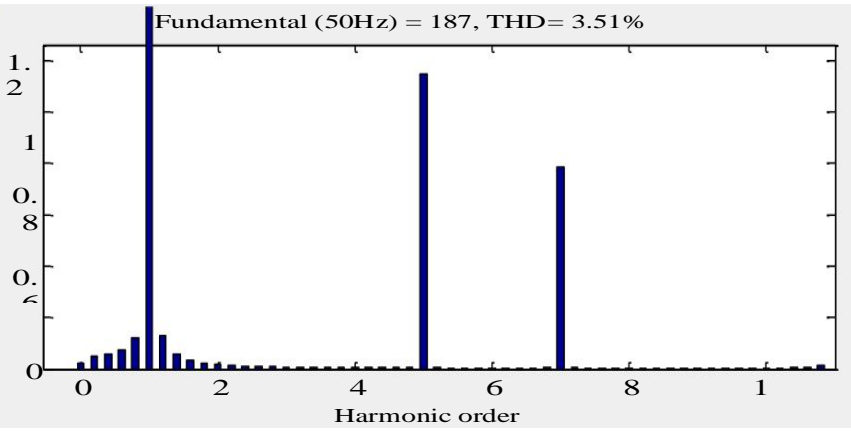

(ii) shows THD of load voltage

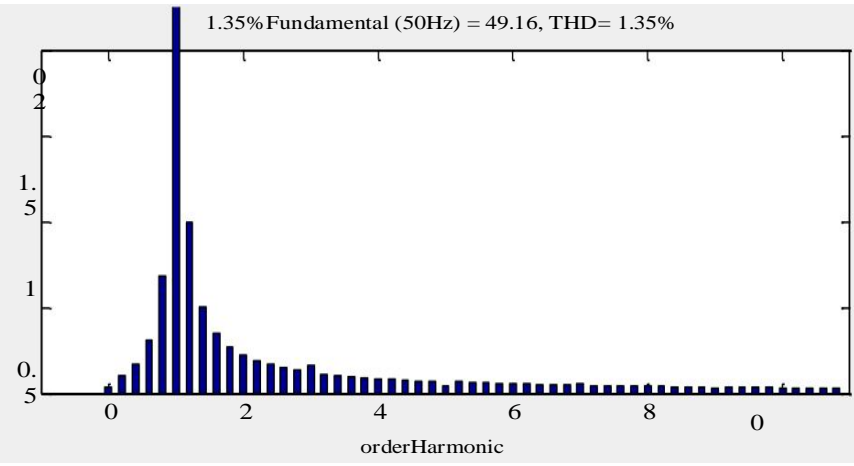

(iii) shows THD of source current

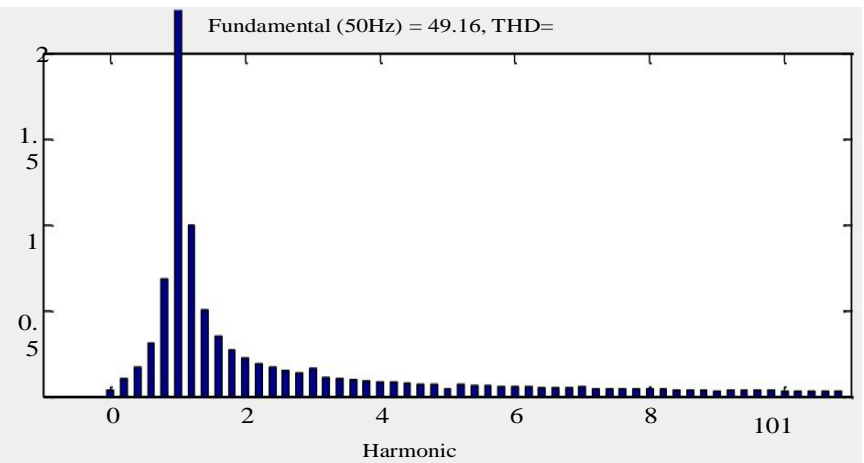

(iv) shows THD of load current 


\section{MATLAB RESULTS}

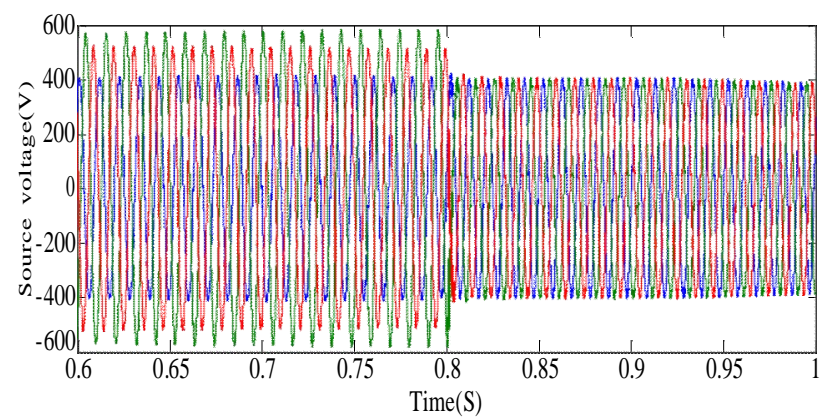

Fig.6: (i) shows Source voltage

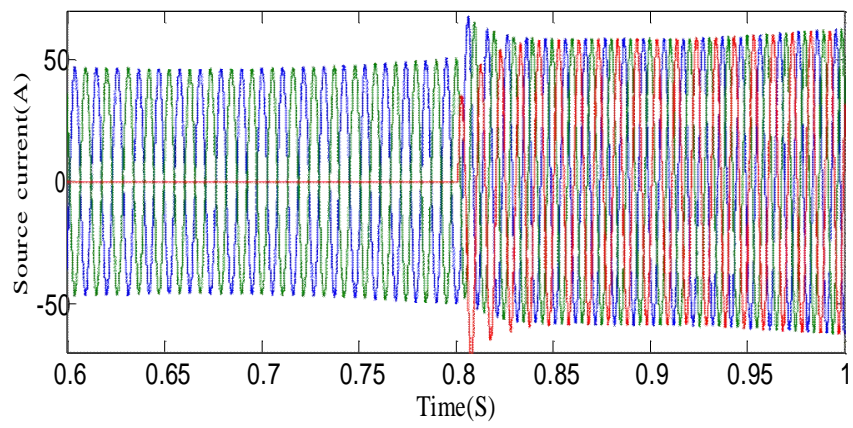

(ii) shows load voltage

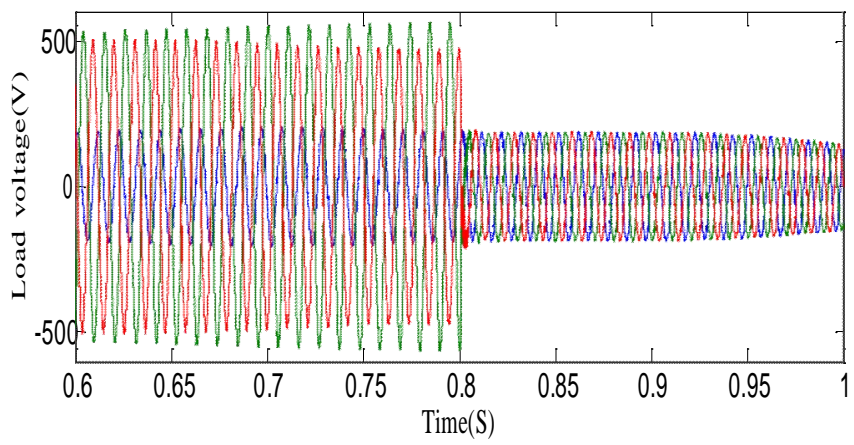

(iii)

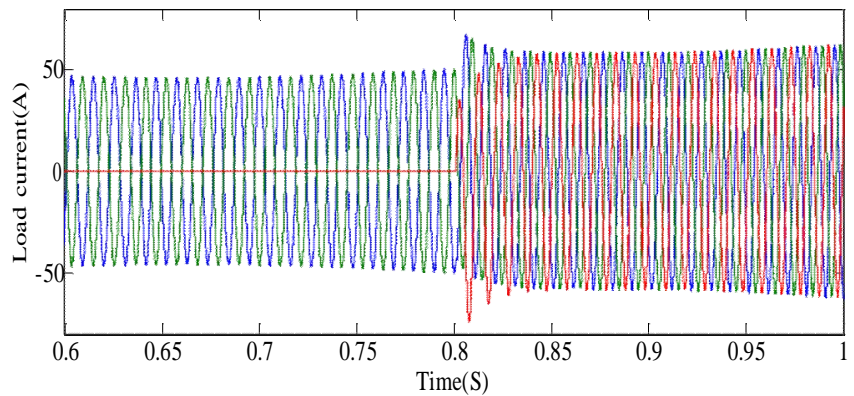

(iv) shows load current

\section{CONCLUSION}

A new control strategy for Dynamic Voltage Restorer (DVR) has been proposed to mitigate the power quality problems in the terminal voltages. The DVR is controlled indirectly by controlling the supply voltage.
The reference supply voltages are estimated using the sensed load terminal voltages and the dc bus voltage of DVR. The control scheme is based on synchronous reference frame theory (SRFT) for the operation of a capacitor supported DVR. The proposed control scheme of DVR has been validated the compensation of sag and swell in terminal voltages. The performance of the DVR has been found very good to mitigate the voltage power quality problems. Moreover, it has been found capable to provide self-supported dc bus of the DVR through power transfer from ac line at fundamental-frequency.

Table 1 shows the performances of voltages and current with and without DVR

\begin{tabular}{|l|l|l|}
\hline Cases & $\begin{array}{l}\text { With DVR } \\
\text { (Balanced) }\end{array}$ & $\begin{array}{c}\text { With DVR } \\
\text { (unbalanced) }\end{array}$ \\
\hline $\begin{array}{l}\text { Source Voltage } \\
\text { (Mag, \%THD) }\end{array}$ & $412.3,0.93$ & $407.8,1.51$ \\
\hline $\begin{array}{l}\text { Load Voltage } \\
\text { (Mag, \%THD) }\end{array}$ & $195.7,2.96$ & $187.0,3.51$ \\
\hline $\begin{array}{l}\text { Source Current } \\
\text { (Mag, \%THD) }\end{array}$ & $58.42,0.20$ & $49.16,1.35$ \\
\hline $\begin{array}{l}\text { Load Current } \\
\text { (Mag, \%THD) }\end{array}$ & $58.42,0.20$ & $49.16,1.35$ \\
\hline
\end{tabular}

As per numerical values the sag and swell magnitudes of the supply voltage have reduced by $90 \%$. The system performance is increased when compared to the condition of sag and swell.

\section{REFERENCES}

[1]R. T. Hock and Y. R.A Voltage Regulator for Power Quality Improvement in Low-Voltage Distribution Grids. IEEE Transactions on Power Electronics.2018; 33(3): 20502060.

[2] Balaga UdayaSri, Patman Rao, Dasumanta Kumar Mohanta, M. Pradeep Chandra Varma, "Improvement of power quality using PQ-theory shunt-active power filter". International conference on Signal Processing, Communication, Power and Embedded System (SCOPES), 2016.

[3]S.R. Arya, M.M. Patel, S.J. Alam, J. Srikakolapu, A.K. Giri, Phase lock loop-based algorithms for DSTATCOM to mitigate load created power qualityproblems, Int. Trans. Elect. Energy Syst. 30 (1) (2020) e12161. 
[4] Ghasemi, M.H. Refan, P. Amiri, An implementation of improved PLL for control of grid- connected converters under grid perturbations, J. Contr. Automat. Elect. Syst. 30 (4) (2019) 568- 579.

[5] Shakir, Pradeep Kumar Bhardwaj, Rambir and Tariq Nafees Khan, "Solution of Power Quality Disturbances in Electrical Distribution Structure with the Introduction of Dynamic Voltage Restorer based on SRFT Control Algorithm", International Journal of Advance Engineering and Research Development, vol. 5, no. 01, pp. 247-254, January 2018, ISSN 2348-4470.

[6] Shakir and M. Sharma, "IRPT Based DVR Application for Voltage Enhancement," 2019 6th International Conference on Signal Processing and Integrated Networks (SPIN), 2019, pp. 34-38, doi: 10.1109/SPIN.2019.8711637. 